\title{
A study of anxiety, depression and stress symptoms among Fayoum medical students during COVID-19 lockdown, Egypt
}

\author{
Mohamed R. Soltan ${ }^{1}$ (1), Shaimaa S. Soliman ${ }^{2}$ (i) and Mariam E. Dawoud ${ }^{3^{*}}$ (1)
}

\begin{abstract}
Background: The widespread pandemic of COVID-19 virus carries not only physical hazards, but also major psychological effects especially among medical students. The aim was to investigate the psychological effects of COVID-19 on medical students and the factors affecting them. The study was carried out with an online questionnaire distributed through Google Forms for medical students at Faculty of Medicine, Egypt. The questionnaire included sociodemographic questions, validated psychometric tools for the assessment of depression, anxiety and stress (Depression Anxiety Stress Scales DASS-21) and the Impact of Event Stress Scale-Revised (IES-R) were applied.

Results: The total number of participants was 282 students. Percentage of participants with clinically significant depression was $75.2 \%$, anxiety was $56.4 \%$ and stress was $52.9 \%$. Those showed PTSD probability was $54.3 \%$. The multivariate regression analysis revealed that IES remained significantly associated with gender and previous road accidents, depression and anxiety remained significantly associated with personal history of psychiatric illness, while stress remained significantly associated with gender and previous road accidents.
\end{abstract}

Conclusions: Medical students were highly depressed, anxious and stressed during period of COVID-19 pandemic. Being a female, having previous history of psychiatric illness and previous road accident were highly associated with increasing the psychological impact of COVID-19.

Keywords: COVID-19, Anxiety, Stress, Depression, Psychological impact

\section{Background}

The novel coronavirus (COVID-2019) pandemic compromises international health concern which has spread very rapidly all over the world an outbreak of acute infectious pneumonia [3]. This large scale, infectious, public health event, had imposed enormous pressure on medical and healthcare providers, and the general public. The epidemic constitutes not only major physical health concern, but also unbearable psychological impact to people in the world $[9,12,17]$.

\footnotetext{
*Correspondence: med11@fayoum.edu.eg

${ }^{3}$ Psychiatry Department, Faculty of Medicine, Fayoum University, POBox: 63514, Faiyum, Egypt

Full list of author information is available at the end of the article
}

The continuous spread of the pandemic, strict isolation measures and delays in starting schools, colleges, and universities across the country is expected to influence the mental health of college students. There are reports on the psychological impact of the epidemic on the general public, patients, medical staff, children, and older adults $[6,10,19]$.

\section{Aim of the work}

The aim of this work was to investigate the psychological distress of COVID-19 (depression, anxiety, stress, and impact of event related stress) on medical students, in Egypt, and to find out different personal risk factors which may provide a theoretical basis for psychological 
interventions to reduce their anticipatory suffering being in direct contact with infectious diseases.

\section{Methods}

\section{Study population and sample}

This is a cross-sectional study approved by the Research Ethics Committee and the Scientific Research Committee, Faculty of Medicine on April 2020. The target population comprised students of Faculty of Medicine, Fayoum University, from the 1st to 6th grade. Psychological impact of these students was assessed using online Google Forms containing structured questionnaire. This online form was available on the offcial Facebook group of the faculty through the period from 1st of May 2020 till the end of June 2020 and each participant can fill it in only once. The questionnaires were anonymous to ensure the confidentiality and reliability of the data. Finally, 282 respondents with valid completed questionnaires were included in the final analysis.

\section{Rating instruments}

The study instrument comprised a structured questionnaire consisted of:

1. Socio-demographic information: gender, grade, past history of abuse, psychiatric disorders and family history of psychiatric disorders.

2. A well-validated psychometric tools for assessment of depression, anxiety and stress (Depression Anxiety Stress Scales DASS-21) and the Impact of Event Stress Scale-Revised (IES-R) in English version. The DASS [11] is a self- report scale which contains three subscales prepared to measure depression, anxiety and tension/stress. It is not categorical a categorical measure of clinical diagnoses. Each subscale contained 7 items. Participants were requested to use 4-point rated scales denoting severity to detect how far they have experienced each impact over the past week. Relevant items for depression, anxiety and stress were summed to calculate the scores. Impact of Event Scale-Revised (IES-R) [18] is a self-report containing 21 items denoting the experienced distress in response to traumatic events being living in the current pandemic situation also hearing news of deaths among medical professionals. Items correspond directly to 14 of the 17 DSM-IV symptoms of PTSD [13]. Respondents were asked to indicate the degree of distress during the past 7 days on each "difficulty" among the questionnaire list using 5-point scale ranging from 0 ("not at all") to 4 ("extremely") in response to COVID-19 as a stress- ful life event. Intrusion, Avoidance, and Hyperarousal subscales' scores can be calculated separately [2].

\section{Statistical analysis of the collected data}

An IBM compatible personal computer with SPSS statistical package version 23 was used to analyze Data (SPSS Inc., 2015. International Business Machines Corporation (IBM) SPSS statistics for windows, Armnok, NY, version 23.0). The variables were expressed in: number (No), percentage (\%) mean $(\bar{x})$ and standard deviation (SD). Association between qualitative variables was assessed using Chi-square test $\left(\chi^{2}\right)$. Fisher's exact test was used in the case that any of the expected cells were less than five. A logistic regression was performed to ascertain the effects of possible risk factors on depression, anxiety and other outcomes. Two sided $p$ value $<0.05$ was considered statistically significant.

\section{Results}

Two hundred eighty-two students participated in this survey. $64.2 \%$ were females, $81.6 \%$ did not have any history of road accidents, $58.5 \%$ did not have any history of psychiatric illness, $78.4 \%$ did not have any family history of psychiatric illness and $69.1 \%$ were worried from

Table 1 Participants' characteristics $(n=282)$

\begin{tabular}{ll}
\hline Character & No. (\%) \\
\hline Age in years (mean \pm SD) & $20.31 \pm 1.61$, \\
Gender & $180.0-22.0$ \\
Male & $101(35.8)$ \\
Female & $181(64.2)$ \\
Previous road accident & \\
No & $230(81.6)$ \\
Yes & $52(18.4)$ \\
History of psychiatric disorders & \\
No & $165(58.5)$ \\
Anxiety & $59(20.9)$ \\
Depression & $41(14.5)$ \\
OCD & $14(5.0)$ \\
Others & $3(1.1)$ \\
Family history of psychiatric disorders & \\
No & $221(78.4)$ \\
Anxiety & $26(9.2)$ \\
Depression & $10(3.5)$ \\
OCD & $11(3.9)$ \\
Others & $14(5.0)$ \\
Worry from working in the medical field in the COVID-19 era \\
No & $87(30.8)$ \\
Yes & $195(69.1)$ \\
\hline
\end{tabular}


Table 2 Results of different scales among the studied group

\begin{tabular}{ll}
\hline Scale & Mean \pm SD \\
\hline Impact of Event Scale-Revised & \\
Total & $34.78 \pm 13.94$ \\
Hyperarousal & $11.52 \pm 5.19$ \\
Avoidance & $11.72 \pm 5.90$ \\
Intrusion & $11.53 \pm 7.56$ \\
DASS & \\
Depression & $21.97 \pm 11.33$ \\
Anxiety & $12.63 \pm 10.38$ \\
Stress & $20.57 \pm 11.36$ \\
\hline
\end{tabular}

working in the medical field. Participants' characteristics are detailed in Table 1.

The mean score of the Impact of Event Scale-Revised total was $34.78 \pm 13.94$. The mean hyperarousal was $11.52 \pm 5.19$, the mean avoidance was $11.72 \pm 5.90$ and the mean intrusion was $11.53 \pm 7.56$. the studied group had mean depression of $21.97 \pm 11.33$, mean anxiety of $12.63 \pm 10.38$ and mean stress of $20.57 \pm 11.36$ (Table 2).

The results of the Impact of Event Scale-Revised were as follows: no impact in $23.45 \%$, clinical concern in 22.3\%, probable PTSD in $9.6 \%$ and high PTSD enough to suppress immunity in $44.7 \%$. Regarding the results of DASS; normal level of depressive symptoms was present in $11.7 \%$, mild in $13.1 \%$, moderate in 25.95 , severe in $11.7 \%$ and extremely severe in $37.6 \%$. Regarding anxiety symptoms, $37.95 \%$ was normal, but mild in $5.7 \%$, moderate in $19.9 \%$, severe in $11.05 \%$ and extremely severe in $25.5 \%$. Normal stress level was present in $19.9 \%$, mild in $27.3 \%$, moderate in $22.0 \%$, severe in $16.7 \%$ and extremely severe in $14.2 \%$ (Table 3 ).

Abnormal IES was only significantly associated with female gender $(p=0.002)$. Any of the studied scales was not significantly associated with history of previous road accidents. Current depression was significantly associated with previous personal history of depression $(p=0.038)$ and current anxiety was significantly associated with personal history of anxiety $(p<0.001)$. Any current psychiatric disorders were not associated with family history of psychiatric disorders. This is detailed in Table 4.

By univariate regression, the IES total score was significantly associated with gender, previous road accidents and personal history of psychiatric illness ( $p$ $0.022,0.018$ and 0.041, respectively). Depression was significantly associated with previous road accidents and personal history of psychiatric illness ( $p 0.038$, $<0.001$, respectively). Anxiety was significantly associated with gender and personal history of psychiatric
Table 3 Prevalence of IES, depression, anxiety and stress symptoms among the studied groups

\begin{tabular}{lc}
\hline Scale & No. (\%) \\
\hline Impact of Event Scale-Revised & \\
No impact & $66(23.4)$ \\
Clinical concern & $63(22.3)$ \\
Probable PTSD & $27(9.6)$ \\
High PTSD enough to suppress immunity & $126(44.7)$ \\
Depression grade & \\
Normal & $33(11.7)$ \\
Mild & $37(13.1)$ \\
Moderate & $73(25.9)$ \\
Severe & $33(11.7)$ \\
Extremely severe & $106(37.6)$ \\
Anxiety grade & \\
Normal & $107(37.9)$ \\
Mild & $16(5.7)$ \\
Moderate & $56(19.9)$ \\
Severe & $31(11.0)$ \\
Extremely severe & $72(25.5)$ \\
Stress grade & \\
Normal & $56(19.9)$ \\
Mild & $77(27.3)$ \\
Moderate & $62(22.0)$ \\
Severe & $47(16.7)$ \\
Extremely severe & $40(14.2)$ \\
\hline
\end{tabular}

illness ( $p 0.033$ and 0.001 , respectively), while stress was significantly associated with gender, previous road accidents, personal and family history of psychiatric illness ( $p 0.024,0.003,0.01$ and 0.032 , respectively) (Table 5).

The multivariate regression analysis of the significant univariate factors revealed that IES remained significantly associated with gender and previous road accidents ( $p 0.015$ and 0.017 , respectively), depression and anxiety remained significantly associated with personal history of psychiatric illness ( $p 0.001$ for each) while stress remained significantly associated with gender and previous road accidents ( $p 0.011$ and 0.004 , respectively) (Table 6).

\section{Discussion}

Medical students are particularly vulnerable to mental health concerns as a result of burden of their academic life and their job description requirements which increase their vulnerability to depression and anxiety. Hence the current pandemic adverse event may increase such negative feelings $[7,8,20]$.

The findings of this study revealed a considerable negative impact on mental health in the studied group 
Table 4 Association between possible risk factor and different scales

\begin{tabular}{|c|c|c|c|c|}
\hline Character & $\begin{array}{l}\text { IES }(n=216) \\
\text { No. }(\%)\end{array}$ & Depression $(n=212)$ & Anxiety $(n=159)$ & Stress $(n=149)$ \\
\hline \multicolumn{5}{|l|}{ Gender } \\
\hline Male & $67(31.0)$ & $72(34.0)$ & $52(32.7)$ & $46(30.9)$ \\
\hline Female & $149(69)^{*}$ & $140(66.0)$ & $107(67.3)$ & $103(69.1)$ \\
\hline$x^{2}$ & 9.23 & 1.27 & 1.53 & 3.35 \\
\hline$p$ value & $0.002^{\dagger}$ & 0.259 & 0.215 & 0.067 \\
\hline \multicolumn{5}{|c|}{ Previous road accident } \\
\hline No & $172(79.6)$ & $174(82.1)$ & $126(79.2)$ & $116(77.9)$ \\
\hline Yes & $44(20.4)$ & $38(17.9)$ & $33(22.8)$ & $33(22.1)$ \\
\hline$x^{2}$ & 2.28 & 0.15 & 1.29 & 2.88 \\
\hline$p$ value & 0.130 & 0.698 & 0.254 & 0.089 \\
\hline \multicolumn{5}{|c|}{ History of psychiatric disorders } \\
\hline No & $118(54.6)$ & $115(54.2)$ & $78(49.1)$ & $82(55.0)$ \\
\hline Anxiety & $52(24.1)$ & $49(23.1)$ & $46(28.9)^{*}$ & $34(22.8)$ \\
\hline Depression & $33(15.3)$ & $36(17.0)^{*}$ & $28(17.6)$ & $25(16.8)$ \\
\hline OCD & $10(4.6)$ & $9(4.2)$ & $5(3.1)$ & $7(4.7)$ \\
\hline Others & $3(1.4)$ & $3(1.4)$ & $2(1.3)$ & $1(0.7)$ \\
\hline FE test & 7.97 & 9.60 & 22.18 & 2.88 \\
\hline$p$ value & 0.079 & $0.038^{\dagger}$ & $<0.001^{\dagger}$ & 0.599 \\
\hline \multicolumn{5}{|c|}{ Family history of psychiatric disorders } \\
\hline No & $169(78.2)$ & $165(77.8)$ & $122(76.7)$ & $113(75.8)$ \\
\hline Anxiety & $18(8.3)$ & $18(8.5)$ & $13(8.2)$ & $14(9.4)$ \\
\hline Depression & $9(4.2)$ & $9(4.2)$ & $8(5.0)$ & $8(5.4)$ \\
\hline OCD & $8(3.7)$ & $8(3.8)$ & $6(3.8)$ & $6(4.0)$ \\
\hline Others & $12(5.6)$ & $12(5.7)$ & $10(6.3)$ & $8(5.4)$ \\
\hline FE test & 2.29 & 2.28 & 4.00 & 3.31 \\
\hline$p$ value & 0.682 & 0.694 & 0.405 & 0.513 \\
\hline
\end{tabular}

$x^{2}$ : Chi-squared test, FE test: Fisher's exact test

${ }^{\dagger} p$ value is significant

* Significantly higher than their corresponding in the same variable

Table 5 Univariate linear regression analysis

\begin{tabular}{llccc}
\hline Character & $\begin{array}{l}\text { IES } \\
\boldsymbol{p} \text { value }\end{array}$ & $\begin{array}{l}\text { Depression } \\
\boldsymbol{p} \text { value }\end{array}$ & $\begin{array}{l}\text { Anxiety } \\
\boldsymbol{p} \text { value }\end{array}$ & $\begin{array}{l}\text { Stress } \\
\boldsymbol{p} \text { value }\end{array}$ \\
\hline Gender & 0.022 & 0.080 & 0.033 & 0.024 \\
Previous road accident & 0.018 & 0.038 & 0.188 & 0.003 \\
History of psychiatric disorders & 0.041 & $<0.001$ & 0.001 & 0.010 \\
Family history of psychiatric disorders & 0.014 & 0.195 & 0.157 & 0.032 \\
\hline
\end{tabular}

Table 6 Multivariate logistic regression analysis

\begin{tabular}{lllll}
\hline Character & IES & Depression & $\begin{array}{l}\text { Anxiety } \\
\boldsymbol{p} \text { value }\end{array}$ & $\begin{array}{l}\text { Stress } \\
\boldsymbol{p} \text { value }\end{array}$ \\
\hline Gender & 0.015 & - & 0.036 & 0.011 \\
Previous road accident & 0.017 & 0.069 & - & 0.004 \\
History of psychiatric disorders & 0.070 & 0.001 & 0.001 & 0.050 \\
Family history of psychiatric disorders & - & - & - & 0.112 \\
\hline
\end{tabular}


in which majority of the participants were experiencing increased stress and anxiety due to COVID-19 pandemic and lockdown.

In this study, according to DASS, those with clinically significant depression were $75.2 \%$. The sum of clinically significant anxiety was $56.4 \%$. Those with clinically significant stress were $52.9 \%$ (Table 3 ). The result of this study was in accordance with the results of a study held in Saudi Arabia where the majority of medical students (73\%) were found to be stressed [1]. Our results were higher than the finding of a study held in India by Vala et al. [15] who used the same psychometric tool and found that depression, anxiety and stress were $15.6,17.2,10.8 \%$, respectively. Yet, only 1 st year medical students were assessed in the last study. Also, our results are higher than survey held in China among college students as all in which the overall incidence of anxiety was $26.60 \%$. Depressive emotions were detected in $21.16 \%$ of the students [5]. Another Chinese study found that deteriorated mental health status among Chinese students [4]. Wang et al. [16, 17] found that in total, $53.8 \%$ of respondents rated the psychological impact of the outbreak as moderate or severe; $16.5 \%$ reported moderate to severe depressive symptoms; those who reported moderate to severe anxiety symptoms was $28.8 \%$; while $8.1 \%$ of the respondents showed reported moderate to severe stress levels. This difference may be due to involvement of large sample among all college students not only medical students.

Regarding IES, the result of this study showed that $9.6 \%$ had the probability for PTSD while, $44.7 \%$ had high PTSD high enough to suppress immunity (Table 3), where females were significantly higher than male (Table 4). This was in line with a study done by Torun and Torun [14] in Turkey also, found that the average scores given to IES- $\mathrm{R}$ in women were also higher $(p=0.02)$.

Regarding association between different variables and psychological impact of COVID-19, the multivariate regression analysis of the significant univariate factors revealed that IES, depression, anxiety and stress are significantly related to gender, history of road accident and personal history of psychiatric disorders (Table 6). Studied variables such as being a female, student status, physical symptoms and poor self-rated health status were found to be significantly associated with a greater levels of stress, anxiety, and depression $(p<0.05)$ as a psychological impact of COVID-19. However, precise health information about treatment and local outbreak situation, particular precautionary measures were associated with and lower levels of stress, anxiety, and depression $(p<0.05)[16]$. Also, the results of multivariate analysis in a study by Chang et al. [5], reported that those who live in rural areas, and reporting negative information regarding the epidemic were more likely to have anxiety. Yet, factors related to likeliness of depression were female gender, residence in suburbs, a drinking history, and excessive negative information concerning the epidemic.

Results of correlation analysis of psychological impact of COVID-19 assessed from Changzhi Medical College in China; indicated that economic effects, and effects on daily routine, and hanging in academic activities, were positively correlated with anxiety symptoms $(p<0.001)$. However, social support was negatively correlated with the level of anxiety $(p<0.001)$ [4]. Cao et al. [4] reported that living with parents was associated with significantly lower rates of severe anxiety in students, while living in rural areas, not having a steady income and recognizing somebody has the infection increased the risk of severe anxiety. These results concerning different studied variables may broaden the scope on the multifactorial nature of the psychological resilience which may affect psychological impact of different life stressors like the period of COVID-19.

\section{Conclusion}

This study supported that medical students significantly affected with distress along the three axes of depression, anxiety and stress during the period of COVID-19 lockdown.

Being a female, having previous history of psychiatric illness and previous road accident were highly associated with increasing the psychological distress of COVID-19.

\section{Limitation of this study}

The students were not motivated to fill in the form. Some recall bias about past traumatic events was not reported accurately by the students. Our research was done only in one medical school so the data cannot be generalized to all medical facilities in Egypt.

\section{Abbreviations}

DASS-21: Depression Anxiety Stress Scales; IES-R: Impact of Event Stress ScaleRevised; PTSD: Post-traumatic stress disorder.

\section{Acknowledgements}

The authors express their deep gratitude to all the participants.

\section{Authors' contributions}

MS prepared the selected methodology and arrange the Google form items. MD prepared the Google form, analyzed and interpreted the patient data regarding the clinical data and psychometric tools and was a major contributor in writing the manuscript. SS was the major contributor in statistical analysis. All authors read and approved the final manuscript.

Funding

This study did not receive any fund.

Availability of data and materials Not applicable. 


\section{Declarations}

\section{Ethics approval and consent to participate}

This study was approved by approved by the Research Ethics Committee, Faculty of Medicine, Fayom University. The number of approval is not applicable. Contents of consent were clarified and written at the start of the electronic questionnaire and approval was necessary to complete the form.

\section{Consent for publication}

Not applicable.

\section{Competing interests}

"No competing interests were declared" in this section.

\section{Author details}

${ }^{1}$ Psychiatry Department, Faculty of Medicine, Fayoum University, Faiyum, Egypt. ${ }^{2}$ Public Health and Community Medicine Department, Faculty of Medicine, Menoufia University, Shibīn al-Kawm, Egypt. ${ }^{3}$ Psychiatry Department, Faculty of Medicine, Fayoum University, POBox: 63514, Faiyum, Egypt.

\section{Received: 19 March 2021 Accepted: 26 August 2021}

Published online: 10 September 2021

\section{References}

1. Abdulghani HM, Sattar K, Ahmad T, Akram A. Association of COVID-19 pandemic with undergraduate medical students' perceived stress and coping. Psychol Res Behav Manag. 2020;13:871.

2. Antony MM, Bieling PJ, Cox BJ, Enns MW, Swinson RP. Psychometric properties of the 42-item and 21-item versions of the Depression Anxiety Stress Scales in clinical groups and a community sample. Psychol Assess. 1998;10(2):176.

3. Bao Y, Sun Y, Meng S, Shi J, Lu L. 2019-nCoV epidemic: address mental health care to empower society. The Lancet. 2020;395(10224):e37-8.

4. Cao W, Fang Z, Hou G, Han M, Xu X, Dong J, Zheng J. The psychological impact of the COVID-19 epidemic on college students in China. Psychiatry Res. 2020;287:112934.

5. Chang J, Yuan Y, Wang D. Mental health status and its influencing factors among college students during the epidemic of COVID-19. Nan fang yi ke da xue xue bao = J South Med Univ. 2020;40(2):171.

6. Chen Q, Liang M, Li Y, Guo J, Fei D, Wang L, He L, Sheng C, Cai Y, Li X, Wang J. Mental health care for medical staff in China during the COVID-19 outbreak. Lancet Psychiatry. 2020;7(4):e15-6. https://doi.org/10.12122/j. issn.1673-4254.2020.02.06

7. Fitzpatrick O, Biesma R, Conroy RM, McGarvey A. Prevalence and relationship between burnout and depression in our future doctors: a crosssectional study in a cohort of preclinical and clinical medical students in Ireland. BMJ Open. 2019;9(4):e023297.
8. Husky MM, Kovess-Masfety V, Swendsen JD. Stress and anxiety among university students in France during Covid-19 mandatory confinement. Compr Psychiatry. 2020;102:152191.

9. Lei L, Huang X, Zhang S, Yang J, Yang L, Xu M. Comparison of prevalence and associated factors of anxiety and depression among people affected by versus people unaffected by quarantine during the COVID-19 epidemic in southwestern China. Med Sci Monit Int Med J Exp Clin Res. 2020;26:e924609-11.

10. Liu X, Liu J, Zhong X. Psychological state of college students during COVID-19 epidemic. Available at SSRN 3552814. 2020.

11. Lovibond PF, Lovibond SH. The structure of negative emotional states: comparison of the Depression Anxiety Stress Scales (DASS) with the Beck Depression and Anxiety Inventories. Behav Res Ther. 1995;33(3):335-43.

12. Pan X, Ojcius DM, Gao T, Li Z, Pan C, Pan C. Lessons learned from the 2019-nCoV epidemic on prevention of future infectious diseases. Microbes Infect. 2020;22(2):86-91.

13. Orsillo Susan M. Measures for acute stress disorder and posttraumatic stress disorder. In: Antony MM, Orsillo SM, editors. Practitioner's guide to empirically based measures of anxiety. New York: KluwerAcademic/Plenum; 2001. p. 255-307 PTSDpubs ID 24368.

14. Torun F, Torun SD. The psychological impact of the COVID-19 pandemic on medical students in Turkey. Pak J Med Sci. 2020;36(6):1355. https://doi. org/10.12669/pjms.36.6.2985

15. Vala NH, Vachhani MV, Sorani AM. Study of anxiety, stress, and depression level among medical students during COVID-19 pandemic phase in Jamnagar city. Natl J Physiol Pharm Pharmacol. 2020;10:1043-5.

16. Wang C, Horby PW, Hayden FG, Gao GF. A novel coronavirus outbreak of global health concern. Lancet. 2020;395(10223):470-3.

17. Wang C, Pan R, Wan X, Tan Y, Xu L, Ho CS, Ho RC. Immediate psychological responses and associated factors during the initial stage of the 2019 coronavirus disease (COVID-19) epidemic among the general population in China. Int J Environ Res Public Health. 2020;17(5):1729.

18. Weiss DS. The impact of event scale: revised. In: Wilson JP, Tang CS, editors. Cross-cultural assessment of psychological trauma and PTSD. Boston: Springer; 2007. p. 219-38.

19. Yang Y, Li W, Zhang Q, Zhang L, Cheung T, Xiang YT. Mental health services for older adults in China during the COVID-19 outbreak. Lancet Psychiatry. 2020;7(4):e19.

20. Zeng Y, Wang G, Xie C, Hu X, Reinhardt JD. Prevalence and correlates of depression, anxiety and symptoms of stress in vocational college nursing students from Sichuan, China: a cross-sectional study. Psychol Health Med. 2019;24(7):798-811.

\section{Publisher's Note}

Springer Nature remains neutral with regard to jurisdictional claims in published maps and institutional affiliations.

\section{Submit your manuscript to a SpringerOpen ${ }^{\circ}$ journal and benefit from:}

- Convenient online submission

- Rigorous peer review

- Open access: articles freely available online

- High visibility within the field

Retaining the copyright to your article

Submit your next manuscript at springeropen.com 